\title{
The Free Kick Kinematics of Elite Football Players
}

\author{
Dujaka Aziz*, Sokoli Bylbyl \\ Faculty of Physical Education and Sport, University Hasan Prishtina, Pristina, Kosovo
}

Email address:

aziz.dujaka@uni-pr.edu (D. Aziz)

${ }^{*}$ Corresponding author

\section{To cite this article:}

Dujaka Aziz, Sokoli Bylbyl. The Free Kick Kinematics of Elite Football Players. International Journal of Sports Science and Physical Education. Vol. 4, No. 2, 2019, pp. 18-27. doi: 10.11648/j.ijsspe.20190402.11

Received: July 7, 2019; Accepted: August 3, 2019; Published: August 16, 2019

\begin{abstract}
We have considered the kinematics parameters for the free instep kick of the elite footballer (Cristiano Ronaldo), in the pace of the swing leg movement and the supporting leg with linear velocity measurement, angular displacement and angular velocity of the joints (ankle, knee, hip). We used the cinematographically method through Kinovea-0.8.26-win32. exe and Photo Suite 4 Platinum Editor from MGI Software of filming of a free instep kick (10. LaLiga, vs. Villarreal, 21/02/2010), and where as the caliber size we have taken the diameter of the ball, creating its kinograms in stages of movement. We have especially analyzed the Approach phase which Cristiano Ronaldo traverses at a distance of $4.0 \mathrm{~m}$, which is passed in 3 steps $(1.14 \mathrm{~m} ; 1.72 \mathrm{~m} ; 2.75 \mathrm{~m})$. Angle of approach is 40 degrees, the free-kick distance is $30 \mathrm{~m}$. During the contact of foot/ball, knee angle of the swing leg is 132 degrees (support leg $153 \mathrm{deg}$ ), while the ball is hit by a linear velocity of ankle joint $17.5 \mathrm{~m} / \mathrm{s}$, giving the ball a speed of $13.7 \mathrm{~m} / \mathrm{s}$. Result of this research is the way of execution the second step of approach phase which Cristiano Ronaldo is performing with the placement of the right foot in the ground only with the tip of the fingers and not with the whole foot, passing quickly backs winging phase, and phase of hip flexion and knee extension during downward motion.
\end{abstract}

Keywords: Instep Free Kick, Kinematics Parameters, Linear Velocity, Angular Displacement, Angular Velocity, Ankle Joint, Knee Joint, Hip Joint

\section{Introduction}

According to studies published on biomechanical analysis of ball kicking in football it is noteworthy that these studies are largely oriented to following numerous variables in different categories of players with the purpose of determining optimal variables for executing a successful kick and in most cases this is determined by the speed of the ball after the strike [1-12]. It is also noted that a general conclusion can be drawn that elite players represent less mechanical variability and the highest velocity of ball impact components compared to beginners or non-professionals [1322].

Primary factors that affect the speed of the kicking foot are rotations of hip and then extension of hip and flexion of ankle just before the ball contact. It is thought that the transfer of the hitch the thigh of leg has a special role, but this conclusion has not yet been fully defined [23-27].

Particularly important are free kicks since they are executed by special positions for which specialist's players, one of whom is obviously Cristiano Ronaldo. The good biomechanical knowledge of ball strikes in football matches is very important in the process of technical perception with young people and in the process of perfection [28].

The purpose of our study is to follow and determine kinematic parameters in soccer free kicking is the instep kick, for the support leg - left foot and swing leg - right foot such as angular displacement, angular velocity and linear displacement per ankle joint, knee joint and hip joint of Cristiano Ronaldo. The information that will be gained through this research will contribute to the perfection of this kick-off in football by improving the learning process especially with young players.

\section{Methods}

\subsection{Subjects}

As we are dealing with an elite player such as Cristiano Ronaldo, who is known for the efficiency of goal scoring from various positions of free kicks, we have selected his 30 
best free blows since 2010, and have chosen those that are best suited for biomechanical analysis from the footage that are found on You Tube.

\subsection{Procedures}

For analysis of the free-kick phase we have chosen the tenth positioned kick (10. LaLiga, vs. Villarreal 21/02/2010). The shooting of this stroke is best suited to that it most satisfies the conditions for biomechanical analysis, where the primary principle is that the camera is fixed (less mobile) and is shot at all stages of the free kick.

Production processing is performed through Software Kinovea-Kinovea Setup. 0.8.15. exe, and Kinovea - 0.8.26win 32. exe, where production shooting is reproduced at speed of 25 shots per second, in a time interval of 0.04 sec. between two frames (phase - frame). This software allows us to directly determine the angles on the joints and the other parts of the body of the player in relation to the space, the ball and the gate.

The extracted photos (25 per second) are displayed through the kinograms for the particular stages of the analyzed motion (free kick) and processed with the aid of the software program Photo Suite 4 Platinum Editor from MGI
Software. This program allows us to increase or decrease the picture in order to preserve the actual spatial dimensions from the fixed point, which in our case has represented the ball before the kick. Kinograms positions represent the time span of 0.04 seconds between two frames (phase - frame). The determination of the path and the linear velocity is realized the caliber constant expressed by the diameter of the soccer ball of size 5 which has a diameter of $22-23 \mathrm{~cm}$ (Soccer ball size).

\subsection{Variables}

The free kick of biomechanical analysis is divided into phases: approach, backswing, hip flexion and knee extension during downwards motion, foot-to-ball contact, deceleration of kicking leg during follow-through [29]. The speed of the soccer ball kick depends on several factors: the speed of the foot before the ball contact, the position of the body at the moment of the ball kick, the length of momentum and the angle of kick [30-32]. In our research, kinematic parameters of the right foot are included, in the swing leg - right foot and the left foot, the support leg - left foot for angle, linear velocity and angular velocity for the last step (Table 1).

Table 1. Kinematic variables selected for analysis are defined.

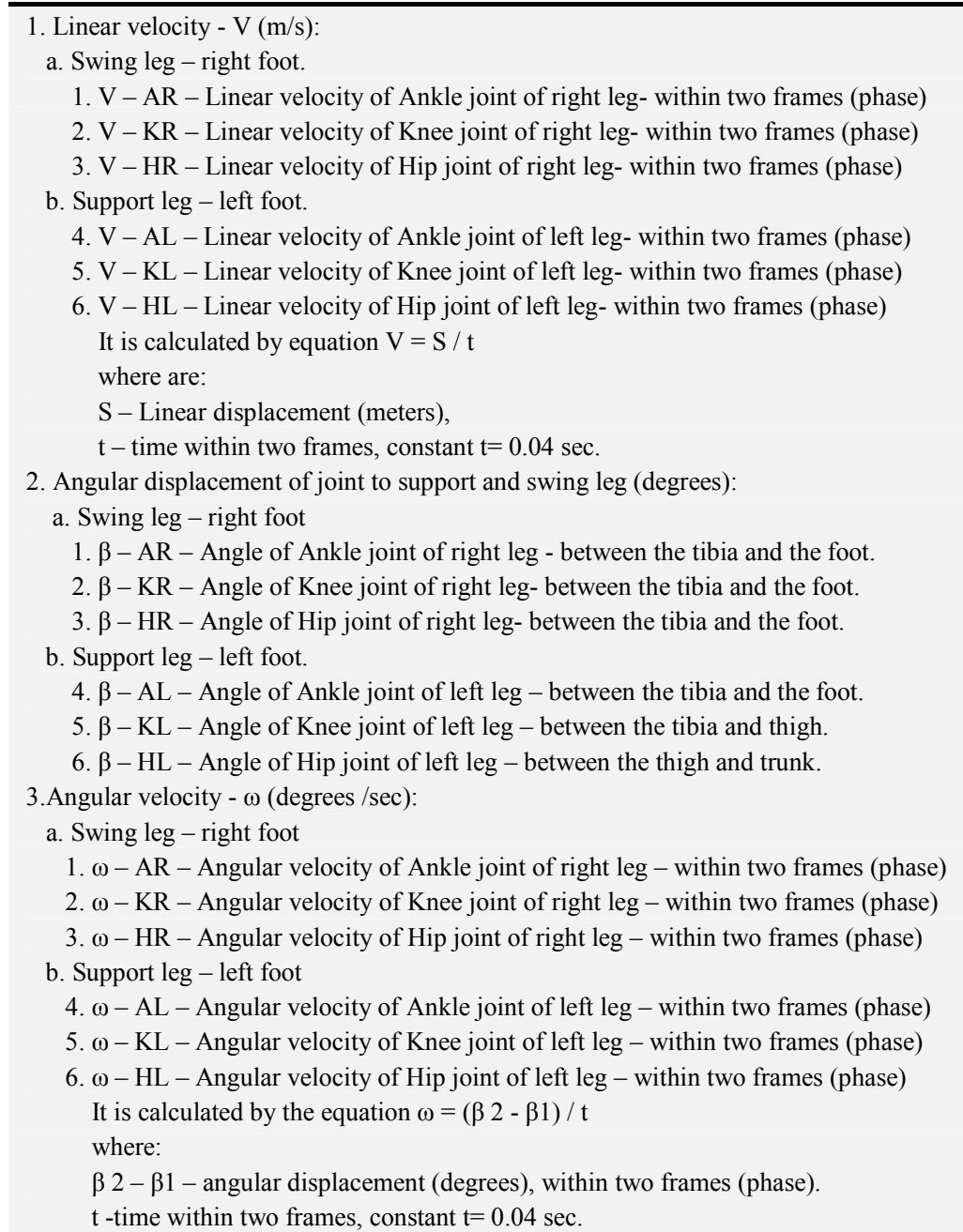




\subsection{Statistical Analysis}

The statistical processing of the results of this research includes the analysis of the free kick kinematic parameters (especially the last step and the ball-kicking stage) of Cristiano Ronaldo. The obtained results are presented through tables and figures during separate free-kick phases. For the results of linear motion velocity, angular displacement and angular velocity kinematics, basic statistical descriptive statistics have been calculated, using the IBM SPSS statistical system version 20 .

\section{Results}

1. Linear velocity $-\mathrm{V}(\mathrm{m} / \mathrm{s})$

a) Linear velocity of joint to swing leg - right foot
(Table 2. -1a, Figure 1, a).

Linear velocity is calculated by linear displacement $(\mathrm{S})$ and t-time within two frames, which in our case is $t=0.04$ sec. The exception is only the space between frames $6-7$ and 7 - 8 (frames 7 it's the impact, foot to ball contact) where $t=$ $0.02 \mathrm{sec}$. The swing leg is immediately followed when the right foot begins to lose contact with the frame when the 3rd stage starts. The ankle joint starts to move at a speed of 6.75 $\mathrm{m} / \mathrm{s}$ and at the end of this phase it reaches $9.5 \mathrm{~m} / \mathrm{s}$. Almost the same result is the joint knee $(6.25-9.25 \mathrm{~m} / \mathrm{s})$ and hip joint (5.50 -7.25 m/s). The joint speed at the beginning of this phase increases to a maximum of $11 \mathrm{~m} / \mathrm{s}$ and then falls to $8 \mathrm{~m} / \mathrm{s}$ and at the foot of ball contact $5 \mathrm{~m} / \mathrm{s}$. Hip joint always during this phase reduces the speed to $3.75 \mathrm{~m} / \mathrm{s}$ and at the end of the foot to ball contact time is $1.5 \mathrm{~m} / \mathrm{s}$.

Table 2. Value of kinematics parameters of free kicking: 1. Linear velocity (V), 2. Angular displacement ( $\beta$ ), 3. Angular velocity ( $\omega)$ of support leg - right foot $(R)$, swing leg - left foot (L), Ankle joint (A), Knee joint (K), Hip joint $(H)$.

\begin{tabular}{|c|c|c|c|c|c|c|c|}
\hline \multicolumn{8}{|c|}{ 1. Linear velocity (V) of joint to support and swing leg (meters/sec) } \\
\hline \multicolumn{4}{|c|}{ a. Swing leg - right foot: } & \multicolumn{4}{|c|}{ b. Support leg - left foot: } \\
\hline Phase-Frames & 1. V-AR (m/s) & 2. V-KR (m/s) & 3. V-HR (m/s) & Phase-Frames & 4. V-AL $(\mathrm{m} / \mathrm{s})$ & 5. V-KL (m/s) & 6. V-HL $(\mathrm{m} / \mathrm{s})$ \\
\hline Phase - 3 & & & & Phase - 3 & & & \\
\hline $1-2$ & 6.75 & 6.25 & 5.50 & $1-2$ & 8.75 & 7.00 & 6.00 \\
\hline $2-3$ & 7.00 & 5.50 & 5.75 & $2-3$ & 8.25 & 6.25 & 6.25 \\
\hline $3-4$ & 9.5 & 9.25 & 7.25 & $3-4$ & 6.25 & 5.00 & 6.50 \\
\hline Phase - 4 & & & & Phase - 4 & & & \\
\hline $4-5$ & 11.75 & 11.00 & 3.75 & $4-5$ & 2.00 & 3.5 & 2.50 \\
\hline $5-6$ & 19.75 & 8.00 & 2.50 & $5-6$ & 1.25 & 2.5 & 2.00 \\
\hline $6-7^{*}$ & 17.50 & 5.00 & 1.50 & $6-7 *$ & 1.00 & 4.00 & 2.50 \\
\hline $\begin{array}{l}\text { Phase - 5** } \\
7^{*}\end{array}$ & & & & $\begin{array}{l}\text { Phase }-5^{* *} \\
7^{*}\end{array}$ & & & \\
\hline Phase - 6 & & & & Phase - 6 & & & \\
\hline $7-8^{*}$ & 13.50 & 6.00 & 5.00 & $7-8^{*}$ & 1.00 & 2.50 & 1.50 \\
\hline $8-9$ & 9.75 & 4.25 & 2.50 & $8-9$ & 0.75 & 1.75 & 1.25 \\
\hline
\end{tabular}

2. Angular displacement ( $\beta$ ) of joint to support and swing leg (degrees): a. Swing leg - right foot:

\begin{tabular}{|c|c|c|c|c|c|c|c|}
\hline a. Swing le & ght foot: & & & b. Support & left foot: & & \\
\hline Frames & 1. $\beta$-AR (deg.) & 2. $\beta$-KR (deg.) & 3. $\beta$-HR (deg.) & Frames & 4. $\beta-A L$ (deg.) & 5. $\beta$-KL (deg.) & 6. $\beta$-HL (deg.) \\
\hline Phase - 3 & & & & Phase - 3 & & & \\
\hline 1 & 135 & 165 & 170 & 1 & 91 & 121 & 97 \\
\hline 2 & 134 & 140 & 182 & 2 & 90 & 142 & 96 \\
\hline 3 & 135 & 117 & 202 & 3 & 95 & 165 & 117 \\
\hline 4 & 141 & 92 & 213 & 4 & 112 & 161 & 133 \\
\hline Phase - 4 & & & & Phase - 4 & & & \\
\hline 4 & 141 & 83 & 213 & 4 & 112 & 161 & 133 \\
\hline 5 & 140 & 73 & 190 & 5 & 120 & 160 & 147 \\
\hline 6 & 122 & 112 & 122 & 6 & 112 & 151 & 130 \\
\hline $7 *$ & 130 & 132 & 99 & $7 *$ & 115 & 153 & 95 \\
\hline Phase - 5* & & & & Phase - 5* & & & \\
\hline $7 *$ & 130 & 132 & 99 & $7 *$ & 115 & 153 & 95 \\
\hline Phase - 6 & & & & Phase - 6 & & & \\
\hline $7 *$ & 130 & 132 & 99 & $7 *$ & 115 & 153 & 95 \\
\hline 8 & 150 & 180 & 95 & 8 & 115 & 153 & 95 \\
\hline
\end{tabular}

\begin{tabular}{|c|c|c|c|c|c|c|c|}
\hline \multicolumn{8}{|c|}{ 3. Angular velocity $(\omega)$ of joint to support and swing leg (degrees / sec) } \\
\hline \multicolumn{4}{|c|}{ a. Swing leg - right foot: } & \multicolumn{4}{|c|}{ b. Support leg - left foot: } \\
\hline Phase - Frames & $\begin{array}{l}\text { 1. } \omega \text {-AR } \\
\text { (deg/sec) }\end{array}$ & $\begin{array}{l}\text { 2. } \omega \text {-KR } \\
\text { (deg/sec) }\end{array}$ & $\begin{array}{l}\text { 3. } \omega \text {-HR } \\
\text { (deg/sec) }\end{array}$ & Phase-Frames & $\begin{array}{l}\text { 4. } \omega \text {-AL } \\
\text { (deg/sec) }\end{array}$ & $\begin{array}{l}\text { 5. } \omega \text {-KL } \\
\text { (deg/sec) }\end{array}$ & $\begin{array}{l}\text { 6. } \omega-\mathrm{HL} \\
\text { (deg/sec) }\end{array}$ \\
\hline $\begin{array}{l}\text { Phase - } 3 \\
1-2\end{array}$ & -25 & -625 & 300 & $\begin{array}{l}\text { Phase - } 3 \\
1-2\end{array}$ & -25 & 525 & -25 \\
\hline
\end{tabular}




\begin{tabular}{|c|c|c|c|c|c|c|c|}
\hline \multicolumn{8}{|c|}{ 3. Angular velocity $(\omega)$ of joint to support and swing leg (degrees / sec) } \\
\hline \multicolumn{4}{|c|}{ a. Swing leg - right foot: } & \multicolumn{4}{|c|}{ b. Support leg - left foot: } \\
\hline Phase - Frames & $\begin{array}{l}\text { 1. } \omega \text {-AR } \\
\text { (deg/sec) }\end{array}$ & $\begin{array}{l}\text { 2. } \omega-\mathrm{KR} \\
\text { (deg/sec) }\end{array}$ & $\begin{array}{l}\text { 3. } \omega-\mathrm{HR} \\
\text { (deg/sec) }\end{array}$ & Phase-Frames & $\begin{array}{l}\begin{array}{l}\text { 4. } \omega-\mathrm{AL} \\
\text { (deg/sec) }\end{array}\end{array}$ & $\begin{array}{l}\text { 5. } \omega-\mathrm{KL} \\
\text { (deg/sec) }\end{array}$ & $\begin{array}{l}\text { 6. } \omega-\mathrm{HL} \\
(\mathrm{deg} / \mathrm{sec})\end{array}$ \\
\hline $2-3$ & 25 & -575 & 500 & $2-3$ & 125 & 575 & 525 \\
\hline $3-4$ & 150 & -625 & 275 & $3-4$ & 425 & -100 & 400 \\
\hline Phase - 4 & & & & Phase - 4 & & & \\
\hline $4-5$ & -25 & -225 & -575 & $4-5$ & 200 & -25 & 350 \\
\hline $5-6$ & -450 & 725 & -1700 & $5-6$ & -200 & -225 & -425 \\
\hline $6-7 *$ & 400 & 2400 & -1150 & $6-7^{*}$ & 150 & 100 & 2000 \\
\hline $\begin{array}{l}\text { Phase - 5** } \\
7 *\end{array}$ & & & & $\begin{array}{l}\text { Phase }-5^{* *} \\
7 *\end{array}$ & & & \\
\hline Phase - 6 & & & & Phase - 6 & & & \\
\hline $7-8^{*}$ & 1000 & 0 & -200 & $7-8^{*}$ & 0 & -650 & 0 \\
\hline $8-9$ & & & & -9 & & & \\
\hline
\end{tabular}

$* \mathrm{t}=0.02 \mathrm{sec}, * *$ impact, foot to ball contact.

b) Linear velocity of joint to support leg-left foot (Table 2.-1b, Figure 1, b)

From the beginning of the movement (frame 1), joint ankle moves at $8.5 \mathrm{~m} / \mathrm{s}$, knee joint at $7 \mathrm{~m} / \mathrm{s}$, hip joint at $6 \mathrm{~m} / \mathrm{s}$, decreasing the speed at the point of kicking with the right foot, ankle joint at $1 \mathrm{~m} / \mathrm{s}$, knee joint at $4 \mathrm{~m} / \mathrm{s}$ and hip joint at $2.5 \mathrm{~m} / \mathrm{s}$. The leg - left foot support role will be discussed in more detail in the Discussion chapter, for which we have followed the kinematic parameters of this limb (support leg).

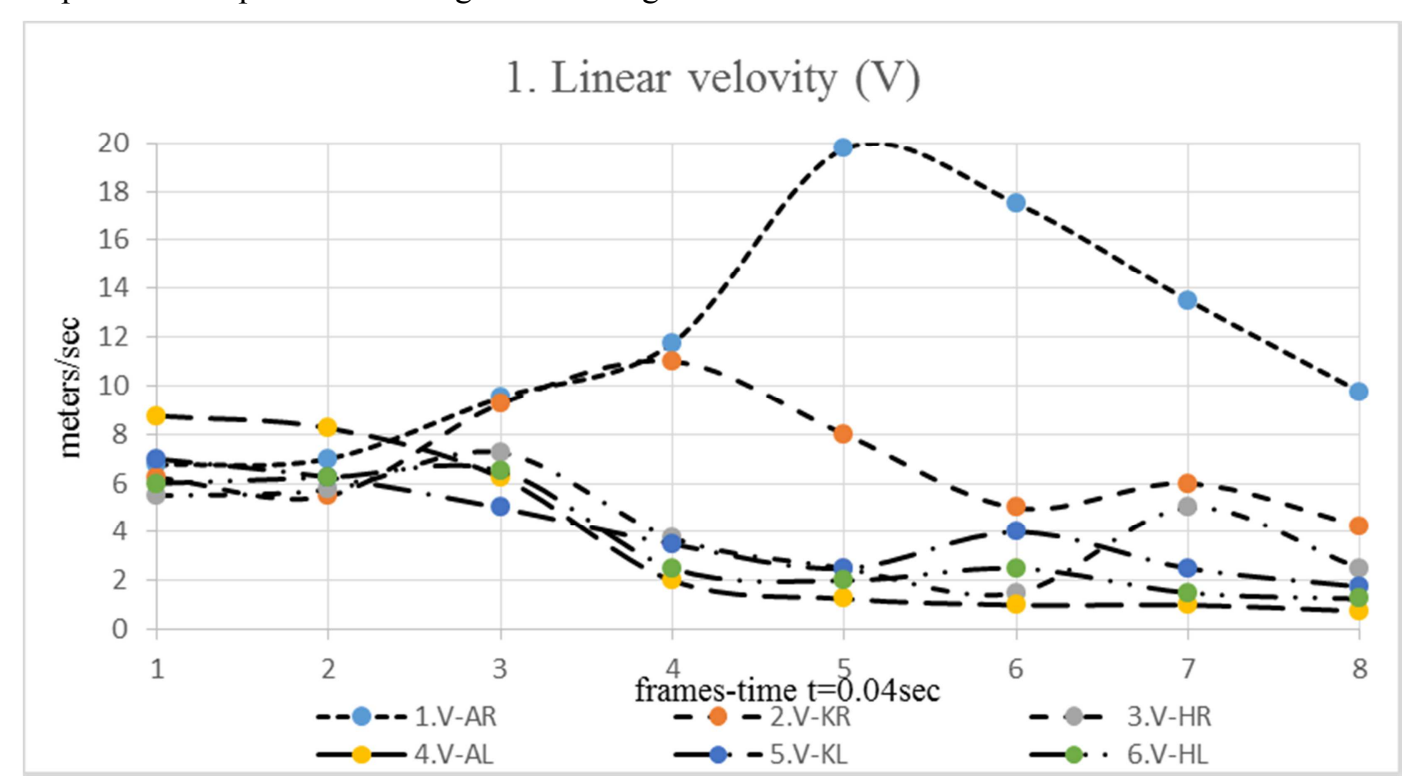

Figure 1. a). Linear velocity of joint to swing leg - right foot: 1. V-AR-Ankle joint, 2. V-KR-Knee joint, 3. V-HR-Hip joint; b). Linear velocity of joint to support leg-left foot: 4. V-AL-Ankle joint, 5. V-KL-Knee joint, 6. V-HL- Hip joint.

\section{c) Linear velocity of ball $(\mathrm{m} / \mathrm{s})$}

In this research the time spent between frames $7-8$ is 0.02 sec, while between frames $8-9$ is $0.04 \mathrm{sec}$, which also defines the linear velocity calculation of the ball in our case study. The linear velocity of the ankle joint to swing leg right foot at the impact moment, the foot to ball contact has a value of $17.5 \mathrm{~m} / \mathrm{s}$, resulting in a ball hit $6.93 \mathrm{~m} / \mathrm{s}$. This speed begins rising between frames $8-9$ and reaches 13.24 $\mathrm{m} / \mathrm{s}$, and between frames $9-10$ is $13.70 \mathrm{~m} / \mathrm{s}$.

\section{Angular displacement $-\beta$ (degrees)}

a) Angular displacement of joint to swing leg - right foot. (Table 2.- 2a, Figure 2, a)

Angular displacement to swing leg of last step is followed by the change of angles from the moment when support leg is stretched (ankle, knee, hip $=180$ deg.) and begins to lose touch with the ground (frame 1) when the 3 phase of swing limb loading - back swing of instep free kicking of soccer begins.

Angular displacement of ankle joint shows small oscillations of values ranging from $135 \mathrm{deg}$. up to $141 \mathrm{deg}$. at the end of this phase. Angular displacement of knee joint from the $165 \mathrm{deg}$ value falls to $92 \mathrm{deg}$, although it should have the minimum value that reaches the beginning of stage 4 , reach the value $83 \mathrm{deg}$. After that, the fierce extension of the knee joint starts and in the 5th stage impact, a value of $132 \mathrm{deg}$. The angular displacement of the hip joint starts at $180 \mathrm{deg}$, reaching a maximum of $213 \mathrm{deg}$. at the beginning of stage 3 of stage 4 . Hip flexion and knee extension during downwards motion and at the end of this phase reaches the 
minimum 99 deg, which will also be in the moment of Impact, foot to ball contact.

b) Angular displacement of joint to support leg - left foot. (Table 2.- 2b, Figure 2, b)

The angular displacement to the support leg of the last step, in all three joints, does not have large oscillations of values. The angular displacement of the ankle joint during the movement over the air has a value of $90-120 \mathrm{deg}$ value and at the moment of foot placement at the ball has a value of
115 deg. Knee joint to support leg - left foot, moves past the value of angle $121 \mathrm{deg}$, and during the phase 4 , has the value of $160 \mathrm{deg}$, to then gain $153 \mathrm{deg}$. at the moment of the foot placement near the ball, which is also maintained during phase 5. Hip joint which supports leg - left foot is worth 97 deg. during phase 4 , when the body is folded back known as body trunk has a maximum value of $147 \mathrm{deg}$. while at the end of this phase is worth $130 \mathrm{deg}$.

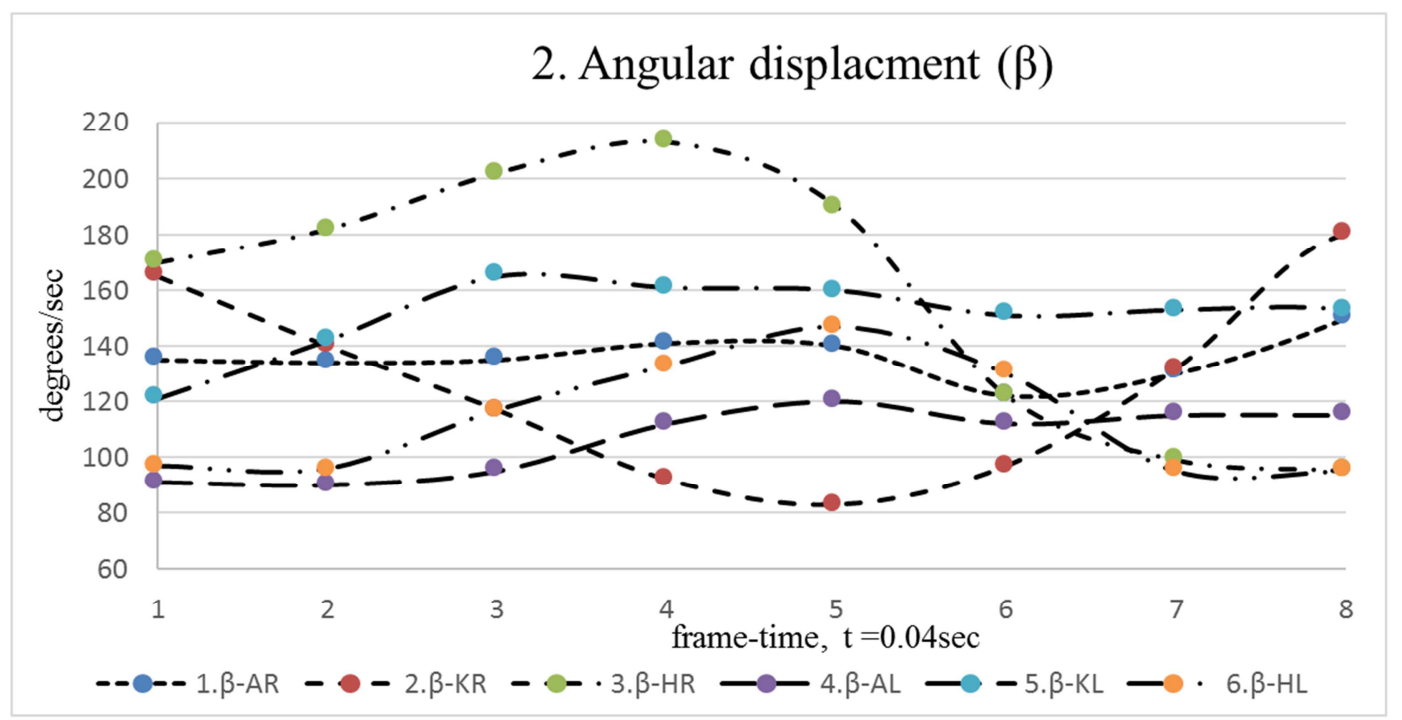

Figure 2. a). Angular displacement of joint to swing leg - right foot: 1. $\beta-$ AR - Ankle joint, 2. $\beta-$ KR-Knee joint, 3. $\beta-H R-H i p$ joint; b). Angular displacement of joint to support leg-left foot: 4. $\beta-A L$ - Hip joint, 5. $\beta-K L$-Knee joint, 6. $\beta-H L$ - Ankle joint.

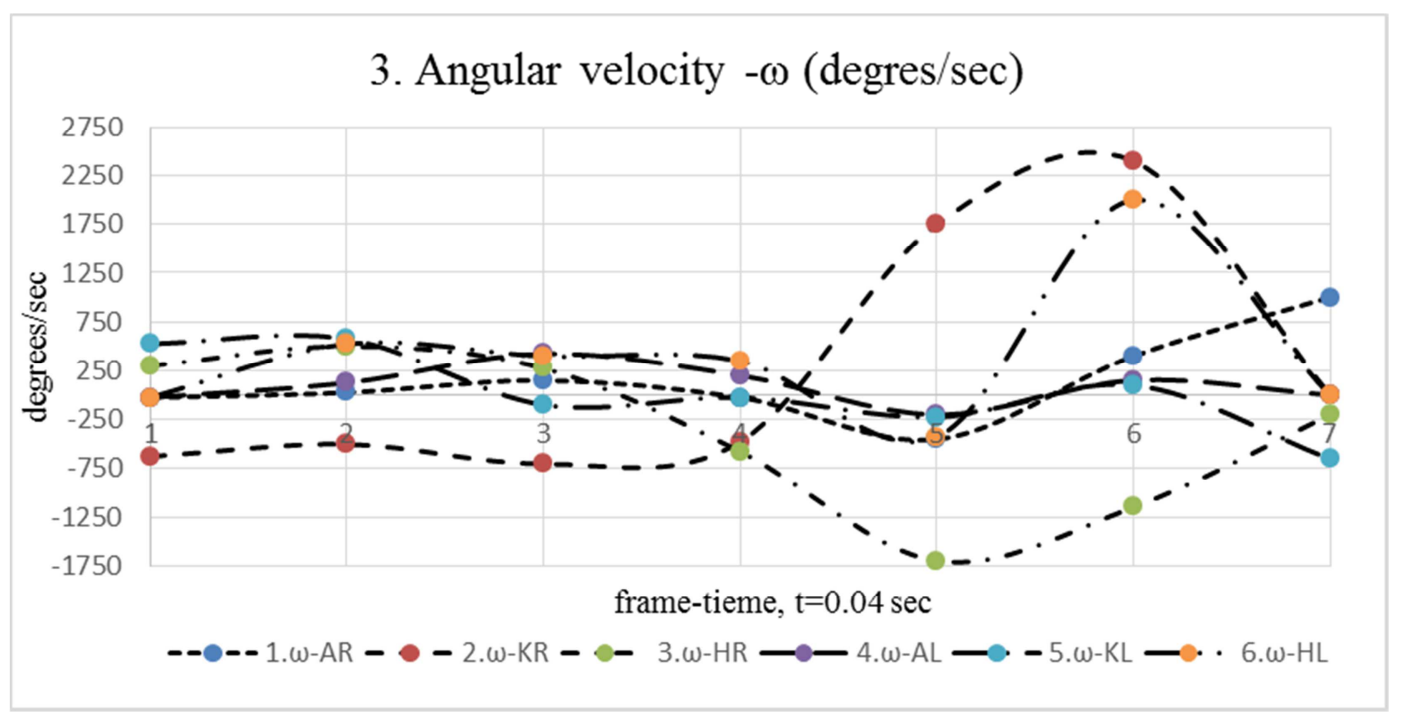

Figure 3. a). Angular velocity of joint to swing leg-right foot: 1. $\omega-$ AR - Ankle joint, 2. $\omega-$ KR-Knee joint, 3. $\omega-H R$ - Hip joint; b). Angular velocity of joint to support leg-left foot: 4. $\omega-A L$-Ankle joint, 5. $\omega-K L$-Knee joint, 6. $\omega-H L$ - Hip joint.

3. Angular velocity - $\omega$ (degrees / sec)

a) Angular velocity of joint to swing leg - right foot (Table 2.- 3a, Figure 3, a)

Angular velocity is calculated by the value of angular displacement $(\beta)$ between two positions (frames $1-2$ and 3 $\left.4, \ldots \mathrm{n}_{1}-\mathrm{n}_{2}\right)$ and the time spent $(\mathrm{t})$ in our case is $\mathrm{t}=0.04 \mathrm{sec}$ (with the exception of the space between frames $6-7$ and 7 8 (frame 7 is the impact, foot to ball contact) where $t=0.04$ sec.

The results with the - (minus) sign show the decrease in angular velocity (deceleration) of the previous position, which in the diagram is presented under the $\mathrm{x}$-axis (axis - $\mathrm{x}$ ) is negative.

Angular velocity of ankle joint after thrust from the ground has a value of $25 \mathrm{deg} / \mathrm{s}$ and at the end of phase 3, reaches $150 \mathrm{deg} / \mathrm{s}$ and at the moment of impact of the ball has a 
value of $400 \mathrm{deg} / \mathrm{s}$. The angle of velocity of the knee joint depends on the angular velocity of the knee joint, when during phase 3 , has a value of $625 \mathrm{deg} / \mathrm{s}$ while in the phase 4 , increases at $725 \mathrm{deg} / \mathrm{s}$. The maximum value is reached at the point of ball impact at $2400 \mathrm{deg} / \mathrm{s}$. Angular velocity of hip joint presented angular velocity (angular displacement) of thigh and trunk. In stage 3, trunk moves forward and at the end of stage 4, spin back, so angular velocity of hip joint oscillates from 300 to $500 \mathrm{deg} / \mathrm{s}$. At stage 5, the trunk passes the whole body movement by tilting the front where the angular velocity has a value of up to $1150-1700 \mathrm{deg} / \mathrm{s}$.

b) Angular velocity of joint to support leg-left foot (Table 2.- 3b, Figure 3, b)

Angular velocity of joint to support leg in all three joints does not show significant changes in value. Angular velocity of ankle joint at stage 3, has a value of $-25 \mathrm{deg} / \mathrm{s}$ and at the end reaches $425 \mathrm{deg} / \mathrm{s}$, while in phase 4 , falls in value 200 $\mathrm{deg} / \mathrm{s}$ and at stage 5, impact foot to ball contact, at $150 \mathrm{deg} /$ $\mathrm{s}$. The angular velocity of the knee joint starts at $525 \mathrm{deg} / \mathrm{s}$ to go down to stage 5, at $100 \mathrm{deg} / \mathrm{s}$. Angular velocity of hip joint has the same results ranging from $525 \mathrm{deg} / \mathrm{s}$ to the 5 th stage at 350-425 deg / s.

\section{Discussion}

1. Approach phase, presents a few moments of impulse that can be executed under a corner with the ball that closes the direction of the ball flight after the strike. The length, speed and angle of approach are the most important aspects of this pre-eminent part that have a significant impact on the soccer kick $[33,34]$. Cristiano Ronaldo's approach phase's distance, which we have analyzed, is $4.0 \mathrm{~m}$, which is passed through 3steps, with the first step being $1.14 \mathrm{~m}$, the second is $1.72 \mathrm{~m}$ and the last step is $2.75 \mathrm{~m}$ (Figure 5). Angle of approach is 40 degrees, while the free-throw distance to the middle of the gate is $30 \mathrm{~m}$. (Figure 4). Two parameters that need to be considered during this phase are the Angled approaches and especially the length of the last step. In their research [35], the different values of angled approaches during run-up affected foot and ball velocities were examined. Their results showed that the maximum swing velocity of the kicking leg was achieved with an approach angle of $30 \mathrm{deg}$, while the maximum ball velocity was achieved with an approach angle of $45 \mathrm{deg}$. From this we can conclude that the most suitable approach angle values are between 30-45 deg. Angle approach also enables the soccer player to be more in touch with the ball for a longer time, thus increasing the accuracy of the kick [36]. Until now, the impact of momentum has not been verified with one step or more steps in the value of the kicked ball speed, but the. Players prefer the usual 2- 3 steps [37], though the study [38], found that the most successful moment is the one with 4.5 and 6 steps.

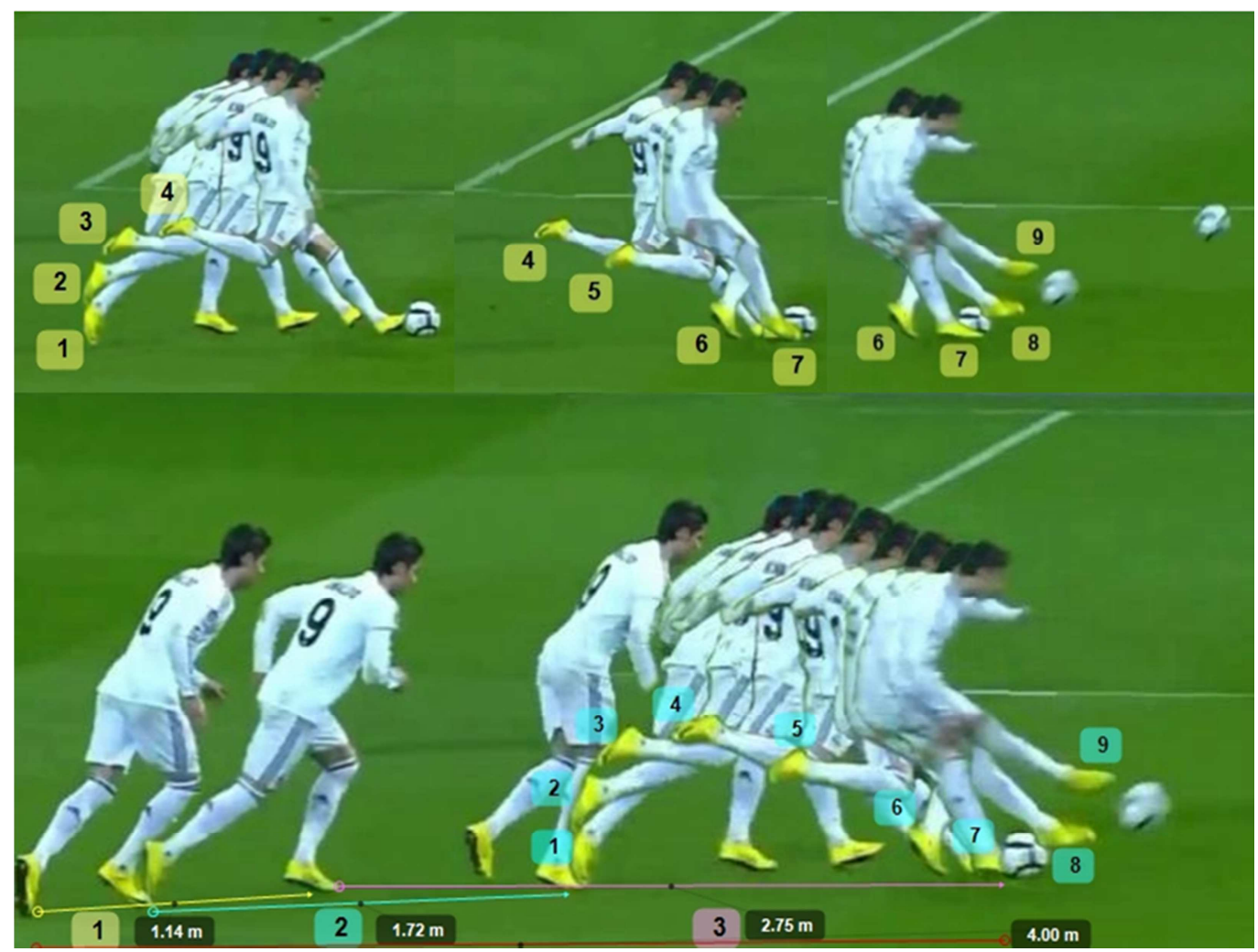

Figure 4. Kinogram of the free kicking phase (3, 4, 5-6) and the whole movement (the running start-access to the ball, 4 meters), the first step 1.14m, second step $1.72 \mathrm{~m}$, and last step $2.75 \mathrm{~m}$.

2. Force production during the foot plant. Prior to the back swing is the force production during the foot plant. The 
position of the foot plant is vital as it determines the balls path [39]. Ground reaction force acting on the support foot during the instep kick should be measured at 1.93-2.67 and 0.5-1.24 time's body weight at impact for the maximum vertical force and maximum horizontal frictional force, respectively [28]. The greater the step when approaching the ball, the more velocity produced through the kicking leg, ultimately generating more power [35].

3. Swing limb loading - backswing starts from frames: 1,2 , 3, 4 (Figure 5), and is characterized with the maximal flexion knee joint and maximal extension hip joint of swing leg. During this time the two lower limbs are in the air, where the support leg continues to move to the ball while the swing leg reaches the value of the flexion angle to the joint $83 \mathrm{deg}$, and the angle velocity $625 \mathrm{deg}$ / sec, while hip joint achieves the maximum value of extension $213 \mathrm{deg}$ (table 2.-2, 3.). This phase ends when the foot of support leg is placed in the ground near the ball. Before the end of this phase, when the hip joint has reached fully extender and the flexed knee, the leg is slowed eccentrically by the hip flexors and knee extensors [40], where the results of our work have values for the ankle join $9.5 \mathrm{~m} / \mathrm{s}$, knee joint $9.25 \mathrm{~m} / \mathrm{s}$ and hip joint $7.25 \mathrm{~m} / \mathrm{s}$.

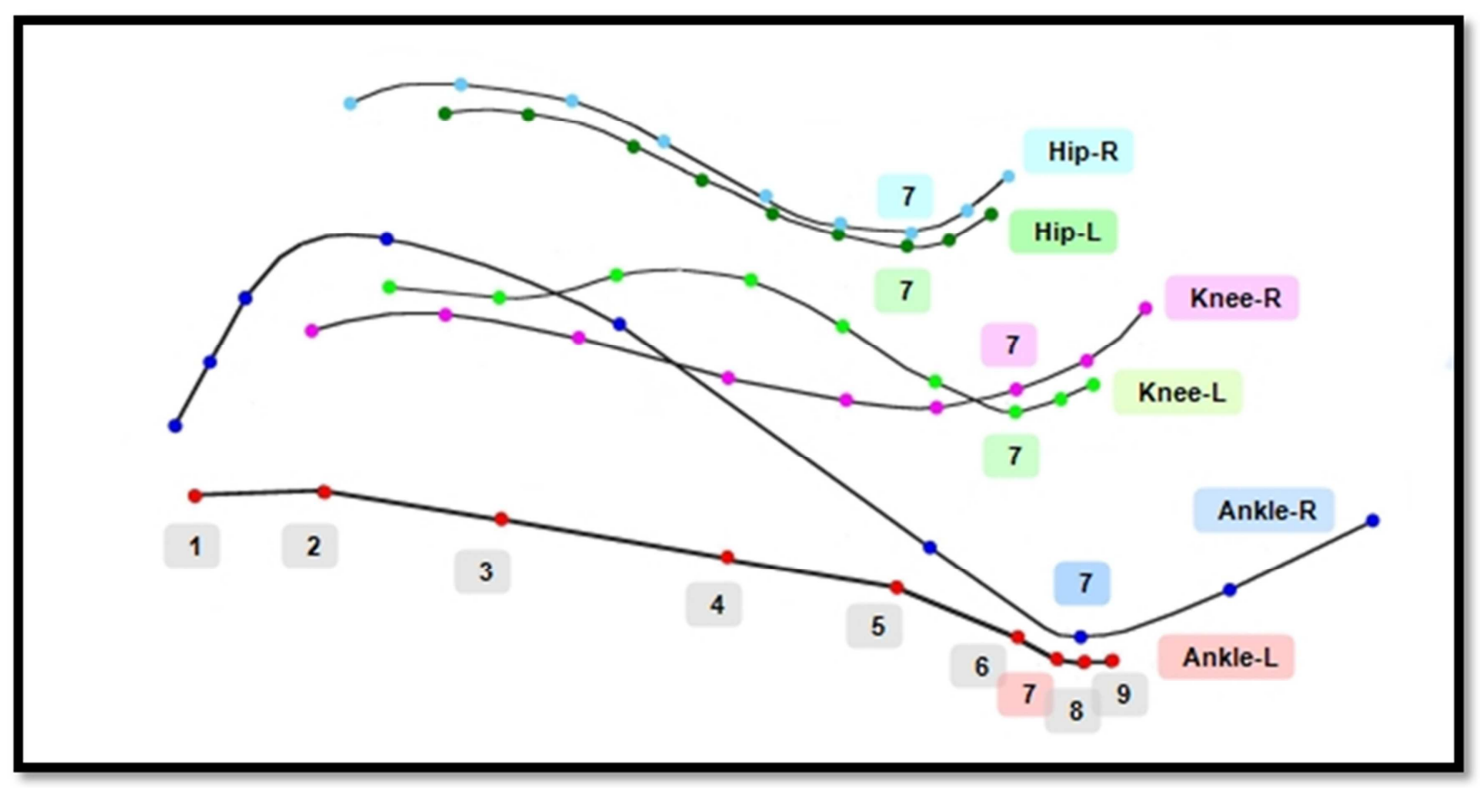

Figure 5. Trajectories of joint to swing (R) and support (L) leg the last step of free kicking in phase: 3. Swing limb loading - backswing (frames: 1, 2, 3, 4), phase 4. Hip flexion and knee extension during downwards motion (frames: 4, 5, 6), phase 5. Foot to ball contact (frames: 7), phase 6. Deceleration of the kicking leg during the follow-through (frames: 7, 8, 9).

4. Hip flexion and knee extension during downwards motion starts from frames: 4, 5, 6 (Figure 5). This stage starts with the swing movement to the ball kick and the tendency is to hit the ball as fast as possible. The results of our work show that the linear velocity of the ankle joint $19.75 \mathrm{~m} / \mathrm{s}$ shortly before the ball kick with the linear with the velocity of ankle joint is $17.75 \mathrm{~m} / \mathrm{s}$, while the ball reaches a speed of $13.70 \mathrm{~m} / \mathrm{s}$. There is a linear relationship between the velocity and the resultant ball velocity [29]. The movement of the upper limbs follows the lower limb movements, so the left arm is back at the side but then moves forward, while the right arm is located backward while maintaining this position even during the next movement. If the movement of the trunk at the beginning of stage 3 is observed, is curved $19 \mathrm{deg}$ from the vertical while at the end of this phase it moves back approaching the 0 degree vertical, in the 4th stage, spins behind the vertical for $5 \mathrm{deg}$., in stage 5 , moves forward and is in vertical position, while in phase 6 , spins forward up to $15 \mathrm{deg}$.
5. Impact, foot to ball contact, frames - 7 (Figure 5). The results of our work are characterized by angle knee of swing leg with the values $132 \mathrm{deg}$ and have maximal angular velocity $2400 \mathrm{deg} / \mathrm{sec}$. Foot contact lasts anywhere from 6 to 16 milliseconds depending on the inflation of the ball [41]. The position of the foot at ball contact as well as well as the distance of the deployment distance foot of support leg may be an important factor not examined in this study because it did not enable the video footage used. Cristiano Ronaldo hits the ball with the inside of the foothold that moves with linear velocity ankle joint $17.50 \mathrm{~m} / \mathrm{sec}$, while the ball starts to move at an initial speed of 6.93 $\mathrm{m} / \mathrm{sec}$, which then rises to $13.70 \mathrm{~m} / \mathrm{sec}$. Research by different authors shows that the foot support of the leg of ball should be $5-10 \mathrm{~cm}$ (dependent on the preferred striking foot) [42, 43]. Support leg at the beginning of the settlement forms the angle with $52 \mathrm{deg}$ and at the end of the kick reaches the angle of $60 \mathrm{deg}$., while the angle between the trunk and the support leg is $137 \mathrm{deg}$ and at the end of the kick reaches the angle $125 \mathrm{deg}$. 
The ankle joint of support leg, at the moment of the ball kick, is worth 153 deg. and allows the amortization phase, with the release of the body it is possible to engage the best contact between the foot / ball thus the speed of impact at soccer elite players is improved [44]. At the ball/foot contact, strong kickers keep the foot / ankle complex locked and tightly plantar flexed so that forces for propelling the ball can be maximized [15, 39, 22.].

6. Deceleration of the kicking leg during the followthrough, frames $-7,8,9$ (Figure 5) is characterized by maintaining the equilibrium position. Left arm is located front - side, right arm is back - side the trunk which is still light flexion. The in - step kick is the deceleration of the kicking leg, linear velocity of swing leg is reduced so the ankle joint is valued with 13.50 $9.75 \mathrm{~m} / \mathrm{s}$, while the joint knee is $6.00-4.25 \mathrm{~m} / \mathrm{s}$, and the other feature is about keeping soccer player safe from the injury after the matches [29]. Which stops because the muscle and elastic forces that have been generated from other phases of the kick are dissipated during the follow through [36]. Towards the end of the follow through phase as the kicking leg extends above the hip, the foot begins to relax and the hip extension brings the leg back down with the athlete ending the phase by landing on the kicking foot [35].

\section{Conclusion}

Based on the results of our research of kinematic parameters, we have ascertained that Cristiano Ronaldo for the analyzed free instep kicking has achieved optimum results. He performs the phase of approach at a distance of 4 $\mathrm{m}$ which he covers in 3 steps where the third step is $2.27 \mathrm{~m}$ long while the angle of approach for shooting at a distance of $30 \mathrm{~m}$, has a value of $45 \mathrm{deg}$. Linear velocity of ankle joint, knee joint and hip joint of phase swing limb backswing, have the value $9.5 \mathrm{~m} / \mathrm{s}, 9.25 \mathrm{~m} / \mathrm{s}$ and $7.25 \mathrm{~m} / \mathrm{s}$. At the end of this phase knee angle of swing leg is $82 \mathrm{deg}$. whereas in hip joint $213 \mathrm{deg}$. At the end of phase hip flexion and knee extension during downwards motion, ankle of knee joint reaches the value $132 \mathrm{deg}$, whereas hip joint $99 \mathrm{deg}$. The support leg when placed next to the ball in the angle of the knee joint is $153 \mathrm{deg}$. The ball is hit with linear velocity of ankle join 17.5 $\mathrm{m} / \mathrm{s}$ giving it start speed of ball $6.93 \mathrm{~m} / \mathrm{s}$ which rises up to $13.70 \mathrm{~m} / \mathrm{s}$.

From these results the role of support leg is also evident which has been researched very little so far. What is worth mentioning as a result of this research is the way of execution of the second step of approach phase which is almost present in all 30 watched footages before those of Cristiano Ronaldo while not appearing or very little executed by top players in soccer. This step is done by setting right foot in the ground only with the tip of his toes and not all the foot, passing very soon on the phase swing limb backswing that further research should show the role and the kinematic values of this step especially for phase force production during the foot plant, or secrecy in the technique of the successful execution of the free kick of Cristiano Ronaldo.

\section{Recommendations}

The further research should show the role and the kinematic values of the second step of approach phase and phase force production during the foot plant, or secrecy in the technique of the successful execution of the free kick especially with young football players. It is necessary to investigate the dependence of the role of the wall, which is inevitable during free-kicking and to see how much the placement of that wall is conditioned by the manner of freekicking in a football game.

\section{Author Contributions}

We declare that contribution to the concept and design of this research is provided by both authors, for selecting of technique football (free kick) by author B. S. while for the realization of biomechanical analysis author A. D. Author of B. S. presented the technical analysis of the free kick, while the biomechanical results of the research were given by author A. D. Both authors have been analyzing and interpreting the results and producing the article, with special contributions from members of the football and biomedical department. The final version approval was also consulted with colleagues from the Institute for Scientific Research of the Faculty of Physical Education and Sports.

\section{Conflict of Interest Statement}

Authors declare that they do not have any conflict of interest. Authors state that there was no financial or personal relationship with other people or organizations that influenced the outcome of this study.

\section{Acknowledgements}

For this research, we thank the Institute of Scientific Research of the Faculty of Physical Education and Sports on the possibilities of using a biomechanics analysis apparatus (processing of the kinograms of movement - free kick) and statistical data processing.

\section{References}

[1] Asai T., Kobayashi K., Oshima Y., 1980. Biomechanical analysis of instep kick in soccer. Proceedings of Japanese Physical Education, 139. [Google Scholar]

[2] Asami T., Nolte V., 1983. Analysis of powerful ball kicking. Biomechanics VIII- B.: Matsui H., Kobayashi K., editors. Champaign, Il: Human Kinetics, 695-700. [Google Scholar]

[3] Barfield, W. R., 1993. Effects of selected biomechanical variables on a coordinated human movement: instep kicking with dominant and nondominant feet. Doctoral dissertation, Auburn University, Auburn, AL. [Google Scholar] 
[4] Barfield, W. R., 1995. Effects of selected kinematic and kinetic variables on instep kicking with dominant and nondominant limbs. Journal of Human Movement Studies 29, 251-272. [Google Scholar]

[5] Barfield W. R., 1997. Biomechanics of kicking. Textbook of Sports Medicine.: Garrett W. E., Kirkendall D. T., editors. Baltimore: Williams \& Wilkins, 86-94. [Google Scholar]

[6] Butterfield, S. A., Loovis E. M., 1994. Influence of age, sex, balance, and sport participation on developemnt of kicking by children in grades K-8. Perceptual and Motor Skills 79, 691697. [PubMed]

[7] Elliott, B. C., Bloomfield J., Davies, C. M., 1980. Development of the punt kick: a cinematographical analysis. Journal of Human Movement Studies 6, 142-150. [Google Scholar]

[8] Kaufmann, D. A., Stanton, D. E., Updyke, W. F., 1975. Kinematical analysis of conventional-style and soccer style place kicking in football. Medicine \& Science in Sports \& Exercise 7, 77-78 (abstract). [Google Scholar]

[9] Luhtanen, P., 1988. Kinematics and kinetics of maximal instep kicking in junior soccer players. Science and Football.: Reilly T., Lees A., Davids K., Murphy W. J., editors. New York: E \& F. N. Spon, 441 - 448. [Google Scholar]

[10] Narici, M. V., Sirtori, M. D., Mognoni, P., 1988. Maximal ball velocity and peak torques of hip flexor and knee extensor muscles. Science and Football.: Reilly T., Lees A., Davids K., Murphy W. J., editors. New York: E \& F. N. Spon, 429 - 433. [Google Scholar]

[11] Olson, J. R., Hunter, G. R., 1985. Anatomic and biomechanical analyses of the soccer style free kick. National Strength and Conditioning Association Journal 7, 50-53. [Google Scholar]

[12] Plagenhoff S. (1971). Patterns of human motion: a cinematographic analysis. Prentice-Hall, Englewood Cliffs, N. J. [Google]

[13] Abo-Abdo, H. E., 1981. Kinematic and kinetic analysis of the soccer instepkick. Doctoral dissertation, Indiana University, Bloomington, IN. [Google Scholar]

[14] Ben-Sira, D., 1980. A comparison of the mechanical characteristics of the instep kick between skilled soccer players and novices. Doctoral dissertation, University of Minnesota, Duluth, MN. [Google Scholar]

[15] Chyzowych, W., 1979. The Official Soccer Book of the United States Soccer Federation. Rand McNally, New York.[Google Scholar]

[16] Dos Anjos, L. A., Adrian, M. J. 1986. Ground reaction forces during soccer kicks performed by skilled and unskilled subjects. Revista Brasileira de Cienias do Esporto (abstract). Sao Paulo, Brazil.[Google Scholar]

[17] Gainor, B. J., Piotrowski, G., Puhl, J. J., Allen, W. C., 1978. The kick: biomechanics and collision injury. American Journal of Sports Medicine 6, 185-193. [Google Scholar]

[18] Hay, J. G., 1996. The biomechanics of sports techniquesfourth edition. Prentice Hall, Englewood Cliffs, NJ. [Google Scholar]

[19] Nishijima, T., Tasaki, E., Noda, Y., Tanaka, K., 1996.
Development of principal motor movements controlling ball kicking performance. ACSM National Meeting Proceedings (abstract). [Google Scholar]

[20] Phillips, S. J., 1985. Invariance of elite kicking performance. Biomechanics IX-B.: Winter D. A., Norman R. W., Wells R. P., Hayes K. C., Patla A. E., editors. Champaign, IL: Human Kinetics Publishers, 539-542. [Google Scholar]

[21] Rodano R., Tavana R. (1993). Three-dimensional analysis of instep kick in professional soccer players. Science and Football II.: Reilly T., Clarys J., Stibbe A., editors. New York: E. \& F. N. Spon, 357-361. [Google Scholar]

[22] Tsaousidis N., Zatsiorsky V. (1996). Two types of balleffector interaction and their relative contribution to soccer kicking. Human Movement Science 15, 861-876. [Google]

[23] Dunn, E. G., Putnam, C. A., 1988. The influence of lower leg motion on thigh deceleration in kicking. Biomechanics XI-B.: deGroot G., Hollander P., Huijing P. A., van Ingen Schenau, G. J., editors. Amsterdam: Free University Press, 787- 790. [Google Scholar]

[24] Huang, T. C., Roberts, E. M., Youm, Y., 1982. Biomechanics of kicking. Human Body Dynamics: Impact, Occupational, and Athletic Aspects.: Ghista, D. J., editor. New York: Clarendon Press \& Oxford University Press; 409-443. [Google Scholar]

[25] Lindbeck, L., 1983. Impulse and moment of impulse in the leg joints by impact from kicking. Journal of Biomechanical Engineering 105, 108-111. [PubMed]

[26] Roberts E. M., Metcalfe A. (1968). Mechanical analysis of kicking. Biomechanics I: Wartenweiler J., Jokl E., Hebbelinck M., editors. Baltimore: University Park Press; 315-319. [Google Scholar]

[27] Robertson D. G. E., Mosher R. E. (1985). Work and power of the leg muscles in soccer kicking. Biomechanics IX-B.: Winter D. A., Norman R. W., Wells R. P., Hayes K. C., Patla A. E., editors. Champaign, IL: Human Kinetics Publishers, 533-53. [Google Scholar]

[28] Kellis, E., \& Katis, A., 2007. Biomechanical characteristics and determinants of instep soccer kick. Journal of sports science \& medicine, 6, 154-165. [PMC]

[29] Barfield, B., 1998. The biomechanics of kicking in soccer. Clinics in Sports Medicine. 17 (4): 711 - 728. [PubMed]

[30] Barfield, W. R., Kirkendall, D. T., \& Yu, B., 2002. Kinematic instep kicking differences between elite female and male soccer players. Journal of sports science \& medicine, 1 (3), 72. [PMC free article]

[31] Meamarbashi, A., \& Hossaini, S., 2010. Application of Novel Inertial Technique to Compare the Kinematics and Kinetics of the Legs in the Soccer Instep Kick. Journal of Human Kinetics, 23, 5-13. [Google Scholar]

[32] Dörge, H. C., Bull-Andersen, T. B., Sørensen, H., and Simonsen, E. B., 2002. Biomechanical differences in soccer kicking with the preferred and the non-preferred leg. Journal of Sports Sciences, 20, 293-299. [Google Scholar]

[33] Isokawa, M. and A. Lees., 1988. A Biomechanical Analysis of the Instep Kick Motion in Soccer. In: Science and Football, Reilly, T., A. Lees, K. Davids and W. J. Murphy (Eds.). E and FN Spon, London, pp: 449-455. [Google Scholar] 
[34] Kellis, E., A. Katis, and I. Gissis., 2004. Knee biomechanics of the support leg in soccer kicks from three angles of approach. Med. Sci. Sports Exerc., 36: 1017-1028. [PubMed]

[35] Lees, A., Asai, T., Andersen, T. B., Nunome, H., \& Sterzing, T., 2010. The biomechanics of kicking in soccer: A review. Journal of Sports Sciences, 28 (8), 805-817. [PubMed]

[36] Garrett, W. E., \& Kirkendall, D. T. (Eds.)., 2000. Exercise and sport science. Lippincott Williams \& Wilkins. [Google Scholar]

[37] A. R. Ismail, M. R. A. Mansor, M. F. M. Ali, S. Jaafar and M. S. N. M. Johar., 2010. Biomechanics Analysis for Right Leg Instep Kick. Journal of Applied Sciences. Volume 10 (13): 1286 - 1292. [Google Scholar]

[38] Reilly, T., \& Williams, A. M. (Eds.). (2003). Science and soccer. Routledge. [Google Scholar]

[39] Hay, J., 1996. Biomechanics of Sport Techniques. Prentice Hall: New Jersey. [Google]

[40] Brown, D. E., \& Neumann, R. D., 2004. Orthopedic secrets. Elsevier Health Sciences. [Google Scholar]

[41] Powers, S, and Howley, E. (1997). Exercise Physiology. Theory and Applications in Fitness and Performance. WCB. McGraw-Hill: Boston. [Google Scholar]
[42] Lees, A., \& Nolan, L., 1998. The biomechanics of soccer. Jurnal of sports science, 16 (3): 211 - 34. [PubMed]

[43] McLean, B. D., \& Tumilty, D. M., 1993. Left-right asymmetry in two types of soccer kick. British Journal of Sports Medicine, 27 (4), 260-262. [PubMed]

[44] Lees, A., Nolan, L., 2002. Three-Dimensional Kinematic Analysis of the Instep Kick Under Speed and Accuracy Conditions: Science and Football IV.: Spinks W., Reilly T., Murphy A., editors. London, Routledge; 16-21. [Google Scholar]

[45] Kinovea - Kinovea. Setup. 0. 8. 15. exe, and Kinovea - 0. 8. 26 win32. exe, (https://www.kinovea.org/).

[46] Photo Suite 4 Platinum Editor from MGI Softwer http://www.sonic.net/mnitepub/pccafe/reviews/photosuite4/ph otosuite4.html.

[47] Soccer ball size $\mid$ Official football size chart, circumference\& weight. https://www.football-bible.com/soccer-info/soccerball-sizes.html.

[48] You Tube - Cristiano Ronaldo TOP 30 Free Kick Goals Ever HD. 